\title{
Bayerisches Jahrbuch
}

100. Jahrgang 2021

\section{Auskunfts- und Adressenwerk}

über die Behörden, Gerichte, Parlamentarischen Körperschaften und die Institutionen im Bereich der Staatsministerien des Freistaates Bayern; die Bezirke, Landkreise, Städte, Gemeinden und Verwaltungsgemeinschaften; über Religionsgemeinschaften; Wirtschafts-, Berufs- und Wohlfahrtsorganisationen; sowie Bundesbehörden;

Diplomatische und Konsularische Vertretungen 
Redaktionsschluss September 2020

Die Redaktion ist für jeden Korrektur- oder Ergänzungsvorschlag seitens der Leserschaft dankbar.

Walter de Gruyter GmbH Redaktion Bayerisches Jahrbuch

Rosenheimer Straße 143

81671 München

Telefon: 089/76902-111

Fax: 089/76902-492

e-mail: Axel.Schniederjuergen@degruyter.com

www.degruyter.com

ISBN 978-3-11-067903-8

e-ISBN 978-3-11-067917-5

e-ISBN (EPUB) 978-3-11-067926-7

ISSN 0174-8386

\section{Bibliografische Information der Deutschen Nationalbibliothek}

Die Deutsche Nationalbibliothek verzeichnet diese Publikation

in der Deutschen Nationalbibliografie;

detaillierte bibliografische Daten sind im Internet über http://dnb.dnb.de abrufbar.

(C) 2021 by Walter de Gruyter GmbH, Berlin/Boston

Satz: bsix information exchange $\mathrm{GmbH}$, Braunschweig

Druck und Bindung: CPI books GmbH, Leck

Printed in Germany

www.degruyter.com 